\title{
A National Communication Campaign in Indonesia Is Associated with Improved WASH-Related Knowledge and Behaviors in Indonesian Mothers
}

\author{
Curtis Hanson ${ }^{1}$, Emily Allen ${ }^{1}$, Margie Fullmer ${ }^{1}$, Rachel O'Brien ${ }^{1}$, Kirk Dearden ${ }^{2}$, \\ Joshua Garn ${ }^{3}$, Cut Novianti Rachmi ${ }^{4}{ }^{\mathbb{D}}$, Jeffrey Glenn ${ }^{1}{ }^{\circledR}$, Joshua West ${ }^{1}$, \\ Benjamin Crookston ${ }^{1}$ (D) and Parley Hall ${ }^{1, *}$ \\ 1 Department of Public Health, Brigham Young University, Provo, UT 84602, USA; \\ curtisha.byu@gmail.com (C.H.); emily.d.allen8@gmail.com (E.A.); fullmerster@gmail.com (M.F.); \\ rachelgoodrich15@gmail.com (R.O.); jeff_glenn@byu.edu (J.G.); josh.west@byu.edu (J.W.); \\ benjamin_crookston@byu.edu (B.C.) \\ 2 IMA World Health, Washington, DC 20036, USA; kdearden@imaworldhealth.org \\ 3 School of Community Health Sciences, University of Nevada, Reno, NV 89557, USA; jgarn@unr.edu \\ 4 Fakultas Kedokteran, Universitas Padjadjaran, Jawa Barat 45363, Indonesia; cutnovianti@gmail.com \\ * Correspondence: cougar_hall@byu.edu
}

Received: 8 May 2020; Accepted: 19 May 2020; Published: 25 May 2020

\begin{abstract}
Background: Water, sanitation, and hygiene (WASH) behaviors play a significant role in stunting. Knowledge and behaviors regarding WASH among caregivers are critical to providing children with chances to survive and thrive. The purpose of this study is to determine if exposure to a national communication campaign using media and interpersonal communication (IPC) is associated with WASH-related knowledge and behaviors among Indonesian mothers with children under the age of two. Methods: Data came from a cross-sectional survey of 1734 mothers with children under the age of two. The measures included exposure to two different interventions: media messages (media) and interpersonal communication strategies (IPC) and WASH-related knowledge and behavior. Multiple logistic regression was used to examine the association between intervention exposure and study variables. Results: Exposure to both media and IPC interventions was associated with participants having a higher knowledge of appropriate defecation practices $(p<0.001)$, higher knowledge of proper handwashing practices $(p<0.001)$, and higher self-reported handwashing at critical times $(p<0.001)$ but was not associated with reported practicing of appropriate defecation $(\mathrm{OR}=0.780,95 \%$ CI: 0.566-1.101). Mothers exposed to only media interventions were more likely to have knowledge of appropriate defecation practices $(p<0.001)$ and to have reported practicing appropriate defecation behaviors (OR $=1.539,95 \%$ CI: 1.173-2.019). Mothers exposed to only IPC interventions were more likely to have reported handwashing at critical times $(p=0.009)$. Conclusions: Exposure to both media and IPC interventions was associated with increased knowledge and optimal behaviors related to WASH. These findings demonstrate the value of communications campaigns that use mass media coupled with IPC to improve WASH knowledge and behavior.
\end{abstract}

Keywords: WASH; media messages; interpersonal communication strategies; knowledge; behavior

\section{Introduction}

Proper water, sanitation, and hygiene (WASH) practices are critical to the physical and mental development of children under the age of two [1]. While several systematic reviews and recent trials assessing WASH and anthropometric outcomes have found either mixed or null results [2-5], some individual studies have found that the prevention of diarrheal disease and undernutrition through proper WASH 
practices helps to decrease the prevalence of stunting [6-13]. Stunting has been shown to correspond with adverse health effects such as decreased cognitive and motor development, lowered performance at school, and reduced productivity in adulthood [14]. The combined effects of stunting are estimated to cost African and Asian nations up to $11 \%$ of their gross national product [15].

Limited access to WASH services presents significant challenges to preventing childhood stunting in Indonesia. Despite Indonesia's emerging economy, the country ranks fifth highest in the world for childhood stunting [16]. Approximately $37 \%$ of children under the age of five are stunted nationwide, a percentage that increases for children in rural regions [17]. A recent study of determinants of stunting in rural Indonesia indicated that $61 \%$ of participant households had an improved sanitary facility, $43.4 \%$ reported safely disposed of a child's feces, $55.3 \%$ used soap for handwashing, and $31.6 \%$ had an improved source of drinking water [18]. It is estimated that approximately $20 \%$ of Indonesians, or 51 million people, defecate in open spaces, such as fields, bushes, and beaches because of limited access to sanitation facilities [19].

In 2014, a social and behavior change campaign called the National Nutrition Communication Campaign (NNCC) was launched in Indonesia. The NNCC included both mass media communications (television, radio, social media) and interpersonal communication (IPC) approaches. Generally IPC strategies include a face-to-face verbal two-way communication inclusive of listening, dialoging, and actioning [20]. In particular, IPC interventions included in the NNCC focused on health workers communicating with mothers at women's groups, maternal health classes, and Posyandu (integrated health post) services for women and children throughout rural Indonesia. The objective of this campaign was to reduce stunting among children in Indonesia by, among other things, improving the WASH behaviors of women and children through mass media efforts and interpersonal communication (IPC). The purpose of this study is to better understand the association between exposure to these various communication interventions and their impact on WASH knowledge and behaviors. In particular, this study aimed to answer the following research questions: (1) Was exposure to NNCC media messages associated with WASH-related knowledge and behaviors? (2) Was exposure to NNCC IPC interventions associated with WASH-related knowledge and behaviors? (3) Was exposure to both NNCC media messages and IPC interventions associated with WASH-related knowledge and behaviors?

\section{Materials and Methods}

\subsection{Design}

Data for this study were collected through a cross-sectional survey conducted in rural Indonesia following the 2014-2018 NNCC intervention and represents a collaborative effort between the IMA World Health (IMA), the University of Indonesia's Center for Nutrition and Health Studies, and the Ministry of Health in Indonesia.

\subsection{Sample}

The study sample consisted of mothers of children under the age of two from three rural districts (Banyuasin, Kubu Raya, and Katingan) located in three provinces (South Sumatera, West Kalimantan, and Central Kalimantan) in Indonesia. A multi-level sampling strategy was used to construct the study sample. One district was randomly selected from each of the three provinces. Within each of the three rural districts, 30 villages were randomly selected, and each represented a cluster unit. At a more local level, four sub-villages were randomly selected from within each of the 30 villages in each of the three districts. Finally, five mothers were selected from each sub-village. The target sample size was 600 mothers from each of the three districts; 1800 total. The actual final study sample included 1734 mothers. 


\subsection{Ethics}

Ethical approval was obtained from the Ethical Research Committee at the Faculty of Public Health, Universitas Indonesia (Ref. 71/H2.F10/PPM.00.02/2018). Reconstra Utama Integra, a research firm from Jakarta, conducted the data collection. Signed informed consent was sought from each participant prior to the interview, and the participation of all subjects was voluntary. Survey data were collected using an electronic tablet by experienced interviewers and field coordinators. Each interviewer interviewed approximately six respondents per day and reported to field coordinators, who then verified the responses and uploaded survey data daily. A data manager checked data and noted any errors. De-identified data were received by the authors from Reconstra Utama Integra to perform the analyses.

\subsection{Data Collection}

Posyandu, the community-based health outpost, was the primary site for IPC interventions. From this facility, participating mothers received postnatal care, growth monitoring and health promotion sessions that were held once monthly and focused on (1) nutrition (maternal, infant, and young child, including breastfeeding, and complementary feeding) and (2) sanitation and hygiene (latrine usage and handwashing). The mothers' participation in IPC programming was completely voluntary.

\subsection{Measures}

Interviewers collected data on participants' demographic information, media and IPC exposure, and WASH knowledge and practices. Demographic information was collected and included the age of the mother and child, the mother's education level, and the total household income level, as represented in Indonesian Rupiah (IDR). To ascertain media exposure, interviewers showed respondents a brief video clip of the TV commercials, or an image of the print media or social media page and asked if they had seen the particular media. Exposure was confirmed by asking the respondent to describe the theme or message in the commercial, print media, or social media. Respondents were considered to have been exposed to the media component if they were able to accurately describe the theme or message of the ad in its various platforms. Exposure to the IPC component was determined by asking respondents if they had participated in classes or support groups for mothers of children under the age of two who meet regularly to share experiences, discuss, and give support for mother and child's health primarily related to pregnancy, breastfeeding, and nutrition which was facilitated by the Posyandu (an Indonesian community-based health outpost). If respondents said yes, they were asked to provide a description of the topics of the meetings. Respondents were considered to be exposed to the IPC component if they were able to accurately describe the topics of the meetings.

Two items were created to represent the participants' knowledge of WASH. A first composite variable was constructed using the participant responses from three questions related to open defecation-the ability to correctly identify (1) at least one of the risks of open defecation (e.g., the transmission of germs, causing diarrhea), (2) at least one medium by which germs could be transmitted to a child from human feces (e.g., fly, water, dirt), and (3) that defecation should occur in a hygienic latrine/toilet (yes/no). A second composite variable was created using participant responses from three questions relating to handwashing - the ability to correctly (1) report the steps involved in proper handwashing (e.g., with soap and clean water), (2) identify the appropriate times for handwashing (e.g., after defecation, before preparing meals, after cleaning a baby), and (3) identify the meaning of CTPS-“Cuci Tangan Pakai Sabun" (handwashing with soap movement). Correct responses to each question resulted in a value of 1 . Each composite variable was the summation of the values for the three corresponding questions. This resulted in four categories for both composite variables: no knowledge, low knowledge, medium knowledge, and high knowledge.

Participants were also asked about two WASH-related behaviors. First, participants reported the extent to which they engaged in appropriate (vs. inappropriate) defecation. Appropriate defecation was defined as using a gooseneck toilet, squat toilet with no floor, or squat toilet with floor, and discarding 
feces in a septic tank or a closed ground hole. Second, participants reported their handwashing behaviors at critical times, which included after defecation, after cleaning a baby, before preparing meals, before eating meals, and before breastfeeding. A frequency measure (0-5) was used to reflect the extent to which they engaged in handwashing at critical times (e.g., never, at one time, two times, three times, four times, or at every critical time).

\subsection{Analysis}

The SAS software version 9.4 (SAS Institute; Cary, NC, USA) was used to conduct all analyses. Demographic data were described using basic frequency statistics. Both linear and logistic adjusted regression models were run for four key dependent variables: (1) knowledge of defecation, (2) knowledge of handwashing, (3) appropriate defecation behavior, and (4) handwashing behavior. Primary independent variables were exposure levels to IPC, media, or both. All models controlled for mother's education, mother's age, and total household income.

\section{Results}

Respondent demographics are presented in Table 1. The mean age for respondents was 27.72 years. Most participants had at least some education, with primary school (38.64\%), junior high school $(24.39 \%)$, and senior high school $(25.03 \%)$ being most common. The majority of respondents indicated that they were unemployed/housewives (87.33\%), with small percentages reporting farming $(2.8 \%)$ and light trade/shop ownership (4.7\%) as forms of employment. Nearly all $(94.58 \%)$ respondents noted Islam as their primary religion.

Table 1. Participant demographics, $N=1734$.

\begin{tabular}{lc}
\hline Demographics & N (\%)/Mean (SD) \\
\hline & Mother \\
Mean Age & $27.72(5.96)$ \\
Education & $97(5.59 \%)$ \\
None & $670(38.64 \%)$ \\
Primary School & $423(24.39 \%)$ \\
Junior High School & $434(25.03 \%)$ \\
Senior High School & $110(6.34 \%)$ \\
Tertiary Education & \\
Occupation & $1468(87.33 \%)$ \\
Unemployed/Housewife & $47(2.80 \%)$ \\
Farmer & $79(4.70 \%)$ \\
Light traders/Shop Owner & $4(0.24 \%)$ \\
Other & $11(87.33 \%)$ \\
Daily/Labor Worker & $6(0.36 \%)$ \\
Fisherman & $25(1.49 \%)$ \\
Private Employee & \\
Religion & $1640(94.58 \%)$ \\
Islam & $94(5.42 \%)$ \\
Other & $1580,2,193,594.18(1,944,608.71)$ \\
Mean Total Household Income (IDR)
\end{tabular}

Note: $N$ is the number of respondents in each category.

Table 2 includes the number of participants who were exposed to NNCC interventions, including media, IPC, and a combination of the two. Nearly half $(48.15 \%)$ of the respondents reported exposure to only NNCC media interventions, while only 3.69\% of the respondents were exposed to only the IPC intervention. Approximately $18 \%$ of respondents reported exposure to both media and IPC. 
Table 2. Exposure to intervention: Media and IPC.

\begin{tabular}{lc}
\hline Exposure & $N(\mathbf{\%})$ \\
\hline No exposure & $522(30.10 \%)$ \\
Exposure to both media and IPC & $313(18.05 \%)$ \\
Exposure to only media & $835(48.15 \%)$ \\
Exposure to only IPC & $64(3.69 \%)$ \\
\hline Note: $N$ is the number of respondents in each category.
\end{tabular}

Detailed knowledge and behavior frequencies are included in Table 3. Nearly half (47.75\%) of the respondents reported high knowledge, and 33.62\% reported medium knowledge of the risks of open defecation. Respondents' knowledge of the benefits of handwashing was lower, with $14.94 \%$ and $37.72 \%$ reporting high knowledge and medium knowledge, respectively. Almost $70 \%$ of the respondents reported engaging in appropriate defecation behaviors. Only $4.79 \%$ of the sample reported washing hands at all critical times, and a larger proportion, $7.26 \%$, reported never washing hands.

Table 3. Knowledge and behavior frequencies.

\begin{tabular}{lc}
\hline Variable & $N \mathbf{( \% )}$ \\
\hline Knowledge & \\
Knowledge of risks of open defecation & $35(2.02 \%)$ \\
No knowledge & $288(16.61 \%)$ \\
Low & $583(33.62 \%)$ \\
Medium & $828(47.75 \%)$ \\
High & \\
Knowledge of benefits of proper handwashing & $204(11.76 \%)$ \\
No knowledge & $617(35.58 \%)$ \\
Low & $654(37.72 \%)$ \\
Medium & $259(14.94 \%)$ \\
High & \\
Behavior & $1212(69.9 \%)$ \\
Appropriate defecation behavior ${ }^{\text {a }}$ & $126(7.27 \%)$ \\
No handwashing & $286(16.49 \%)$ \\
Washed hands at one critical time & $443(25.55 \%)$ \\
Washed hands at two critical times & $490(28.26 \%)$ \\
Washed hands at three critical times & $306(17.65 \%)$ \\
Washed hands at four critical times & $83(4.79 \%)$ \\
Washed hands at five critical times &
\end{tabular}

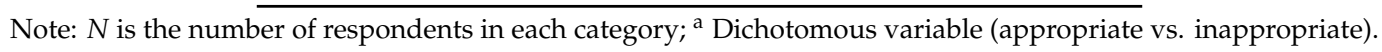

Table 4 includes results of the linear regression models testing for associations between exposure to the NNCC interventions and knowledge of defecation and handwashing. Exposure to a combination of both media and IPC $(p<0.001)$ and exposure to only media $(p<0.001)$ were associated with increased knowledge of defecation. Exposure to a combination of both media and IPC was associated with an increased knowledge of handwashing $(p<0.001)$, while there was no statistically significant association with exposure to only media or to only IPC. 
Table 4. Regression analysis with knowledge for defecation and handwashing.

\begin{tabular}{lc}
\hline Exposure & Adjusted Beta Estimate $(p \text {-Value })^{\text {a }}$ \\
\hline Knowledge of Defecation Model & $0.402(<0.001)^{* * *}$ \\
Exposure to both media and IPC & $0.198(<0.001)^{* * *}$ \\
Exposure to only media & $0.133(0.193)$ \\
Exposure to only IPC & \\
Knowledge of handwashing model & $0.340(<0.001)^{* * *}$ \\
Exposure to both media and IPC & $0.057(0.253)$ \\
Exposure to only media & $0.131(0.258)$ \\
Exposure to only IPC & \\
\hline
\end{tabular}

a Linear regression model; Reference group = no exposure; Each model adjusted for mother's education, mother's age, and total household income. ${ }^{* * *} p<0.001$.

Table 5 includes results of the logistic and linear regression models testing for associations between exposure to the NNCC interventions and appropriate defecation and handwashing behaviors. Exposure to only media was associated with appropriate defecation behavior (OR 1.539, CI 1.173-2.019), while there was no statistically significant association with exposure to only IPC or to both media and IPC. Exposure to both media and IPC $(p<0.001)$ and exposure to only IPC $(p<0.05)$ were associated with better handwashing behaviors while there was no statistically significant association with exposure to only media.

Table 5. Regression analysis with behavior for defecation and handwashing.

\begin{tabular}{|c|c|c|}
\hline Exposure & Adjusted Beta Estimate ( $p$-Value) ${ }^{a}$ & Adjusted OR $(95 \% \mathrm{CI})^{b}$ \\
\hline \multicolumn{3}{|l|}{ Appropriate defecation model } \\
\hline Exposure to both media and IPC & - & $0.780(0.566-1.101)$ \\
\hline Exposure to only media & - & $1.539(1.173-2.019) *$ \\
\hline Exposure to only IPC & - & $0.573(0.322-1.017)$ \\
\hline \multicolumn{3}{|l|}{ Handwashing at critical times model } \\
\hline Exposure to both media and IPC & $0.349(<0.001)^{* * *}$ & - \\
\hline Exposure to only media & $0.0276(0.543)$ & - \\
\hline Exposure to only IPC & $0.2693(0.009)^{* *}$ & - \\
\hline
\end{tabular}

\section{Discussion}

The purpose of this study was to determine if exposure to either media, interpersonal communication (IPC), and a combination of both in a large social and behavior change campaign was associated with increases in WASH knowledge and behaviors among mothers with children under the age of two. The results show that a combination of both media and IPC interventions was closely associated with improved knowledge about both defecation and handwashing, while exposure to media alone was associated with knowledge about defecation but not about handwashing.

Findings from this study are consistent with other studies that have shown a positive impact of media on child health practices. For example, a systematic review of mass media's impact on child health found that among 32 studies deemed methodologically rigorous, 26 showed a positive impact of mass media on self-reported health behaviors [21]. Similarly, a review of a national handwashing campaign in Ghana found the intervention reached over $80 \%$ of the population and noted that a combination of radio and television messaging had greater impacts on knowledge and behavior than community events [22].

Findings indicate that media messages like television, radio, and social media platforms implemented in the NNCC may best be suited for addressing or promoting knowledge and behavior related to defecation. One explanation for this finding may be the intimate nature of defecation and 
relative social discomfort with discussing defecation in a face-to-face setting. It may also be that open defecation, although relatively common in rural Indonesia, is nonetheless stigmatized and is thus less comfortable for both community health workers and mothers to discuss openly. In this case, media interventions offer a potential level of privacy at point of exposure that would be difficult, if not impossible, to achieve with IPC.

Mass media has the potential to extend the reach of health messaging across diffused populations like Indonesia, where 261 million residents are dispersed across 17,000 islands and 75,000 villages [23]. The media approach used in the NNCC was inclusive of social media, which may additionally help to reinforce the status of frontline health workers as educated, trusted, and accessible to community members [23]. Given the widespread lack of knowledge about stunting in rural Indonesia, the use of multiple media channels in the NNCC might have extended campaign coverage and may have encouraged behavior change. Wakefield, Loken, and Hornik [24] credit the effectiveness of mass media for promoting health behaviors to several key factors, including (1) removing emotional or cognitive obstacles to change, (2) helping people to either adopt healthy social norms or recognize unhealthy social norms, (3) associating valued emotions with achieving change, and (4) strengthening intentions for achieving behavior change. While the current study explored associations between media exposure and WASH-related knowledge and behaviors, future studies may continue to explore and verify the why and how of media impacts.

Exposure to only NNCC IPC interventions in this study was associated with one behavioral indicator for handwashing, while media-only exposure was not associated with any handwashing measure. It may be that IPC interventions, including the women's groups, maternal health classes, and Posyandu services for women utilized in the NNCC, are best suited for addressing or promoting knowledge and behavior related to handwashing. Perhaps handwashing instruction, including modeling and practicing proper technique, is best accomplished through interpersonal communication and in settings where both knowledge of, and practice with, this important behavior can be accomplished. It is noted that standard approaches to WASH promotion, including face-to-face instructions, focused on educating individuals on the value of handwashing with soap following critical incidents, have been shown to have limited long-term impact on behavior change [25-29]. An exception to this finding is a small IPC intervention where Indonesian mothers were taught hand hygiene by community health workers and were provided free soap. A two-year follow up found that nearly $80 \%$ of participants were still using hand soap, despite the fact that it was no longer provided to them free of charge [30]. In this case, the face-to-face education provided by trusted community health workers may have made the difference. Greenland et al. note the effectiveness of IPC interventions increases when new mothers are targeted, and the information comes from trusted others, primarily grandmothers and midwives [31]. The current study is unable to measure the long-term impact of NNCC IPC strategies on WASH behaviors, yet the inclusion of women's group instruction, maternal health classes, and Posyandu services provided by midwives provides hope that the significant impact of IPC identified in this study may be long-lasting.

The results from this study should be considered with several key limitations. This study was cross-sectional, and, therefore, unable to demonstrate a causal relationship between exposure to NNCC interventions and knowledge or behavior of study variables. Second, the study lacked sufficient power to be able to detect small effects, particularly for those variables with insufficient numbers of responses. In particular, limited numbers of participants exposed to IPC interventions may have prevented additional significant findings. Third, much of the data analyzed resulted from participant's self-report and recall of exposure to NNCC programming and are therefore susceptible to error. Fourth, participants came from three rural regions of Indonesia, which are not representative of the country as a whole, greatly limiting the ability to generalize results. Finally, the temporal variance of exposure to NNCC programming and timing of the subsequent data collection may have impacted participant recall and impacted the study results. However, the research is still highly relevant as reaching rural communities is integral to the Sustainable Development Goal to achieve access to adequate and 
equitable sanitation and hygiene for all and end open defecation". Finally, this study did not use an asset index to measure poverty, which is traditionally used as an indicator of wealth in developing settings. Since the indicators necessary to construct such an index were not included in the study survey, a measure of total household income was used instead.

\section{Conclusions}

In conclusion, analysis of exposure to media and IPC interventions included in the NNCC show that exposure to both IPC and media interventions were associated with improved knowledge and behaviors related to WASH. These findings demonstrate the value of communications campaigns that use mass media coupled with IPC to improve WASH knowledge and behavior. Media campaigns may be helpful when addressing knowledge and behaviors for appropriated defecation, while IPC interventions appear well-suited for promoting handwashing behavior.

Author Contributions: Conceptualization, C.H., C.N.R., J.W. and B.C.; methodology, C.H. and J.W.; validation, C.N.R.; formal analysis, C.H., J.W. and B.C.; resources, C.N.R. and K.D.; writing-original draft preparation, C.H., E.A., M.F., R.O. and P.H.; writing-review and editing, K.D., P.H., J.G. (Joshua Garn), J.W., B.C. and J.G. (Jeffrey Glenn); supervision, C.H. and P.H. All authors have read and agreed to the published version of the manuscript.

Funding: This research received no external funding.

Acknowledgments: This study was made possible by IMA-World Health.

Conflicts of Interest: The authors declare no conflict of interest.

\section{References}

1. $\quad$ Black, R.E.; Allen, L.H.; Bhutta, Z.A.; Caulfield, L.E.; De Onis, M.; Ezzati, M.; Mathers, C.; Rivera, J.; Maternal and Child Undernutrition Study Group. Maternal and child undernutrition: Global and regional exposures and health consequences. Lancet 2008, 371, 243-260. [CrossRef]

2. Cumming, O.; Cairncross, S. Can water, sanitation and hygiene help eliminate stunting? Current evidence and policy implications. Matern. Child Nutr. 2016, 12, 91-105. [CrossRef] [PubMed]

3. Freeman, M.C.; Garn, J.V.; Sclar, G.D.; Boisson, S.; Medlicott, K.; Alexander, K.T.; Penakalapati, G.; Anderson, D.; Mahtani, A.G.; Grimes, J.E.; et al. The impact of sanitation on infectious disease and nutritional status: A systematic review and meta-analysis. Int. J. Hyg. Environ. Health 2017, 220, 928-949. [CrossRef]

4. Luby, S.P.; Rahman, M.; Arnold, B.F.; Unicomb, L.; Ashraf, S.; Winch, P.J.; Stewart, C.P.; Begum, F.; Hussain, F.; Benjamin-Chung, J.; et al. Effects of water quality, sanitation, handwashing, and nutritional interventions on diarrhoea and child growth in rural Bangladesh: A cluster randomised controlled trial. Lancet Glob. Health 2018, 6, e302-e315. [CrossRef]

5. Null, C.; Stewart, C.P.; Pickering, A.J.; Dentz, H.N.; Arnold, B.F.; Arnold, C.D.; Benjamin-Chung, J.; Clasen, T.; Dewey, K.G.; Fernald, L.C.; et al. Effects of water quality, sanitation, handwashing, and nutritional interventions on diarrhoea and child growth in rural Kenya: A cluster-randomised controlled trial. Lancet Glob. Health 2018, 6, e316-e329. [CrossRef]

6. Esrey, S. Water, waste, and well-being: A multicountry study. Am. J. Epidemiol. 1996, 143, 608-623. [CrossRef] [PubMed]

7. Fink, G.; Gunther, I.; Hill, K. The effect of water and sanitation on child health: Evidence from the demographic and health surveys 1986-2007. Int. J. Epidemiol. 2011, 40, 1196-1204. [CrossRef]

8. Pickering, A.J.; Djebbari, H.; Lopez, C.; Coulibaly, M.; Alzua, M.L. Effect of a community-led sanitation intervention on child diarrhoea and child growth in rural Mali: A cluster-randomised controlled trial. Lancet Glob. Health 2015, 3, e701-e711. [CrossRef]

9. Spears, D. How much international variation is child height can sanitation explain? In World Bank Policy Research Paper; No WPS 6351; World Bank: Washington, DC, USA, 2013.

10. Spears, D.; Ghosh, A.; Cumming, O. Open defecation and childhood stunting in India: An ecological analysis of new data from 112 districts. PLoS ONE 2013, 8, e73784. [CrossRef] 
11. Rah, J.; Cronin, A.; Badgaiyan, B.; Aguayo, V.; Coates, S.; Ahmed, S. Household sanitation and personal hygiene practices are associated with child stunting in rural India: A cross-sectional analysis of surveys. BMJ Open 2015, 5, e005180. [CrossRef]

12. Checkley, W.; Gilman, R.H.; Black, R.E.; Epstein, L.D.; Cabrera, L.; Sterling, C.R.; Moulton, L.H. Effect of water and sanitation on childhood health in a poor Peruvian periurban community. Lancet 2004, 363, 112-118. [CrossRef]

13. Fenn, B.; Bulti, A.; Nduna, T.; Duffield, A.; Watson, F. An evaluation of an operations research project to reduce childhood stunting in a food-insecure area in Ethiopia. Public Health Nutr. 2012, 15, 1746-1754. [CrossRef] [PubMed]

14. Black, R.E.; Victora, C.G.; Walker, S.P.; Bhutta, Z.A.; Christian, P.; De Onis, M.; Ezzati, M.; Grantham-McGregor, S.; Katz, J.; Martorell, R.; et al. Maternal and child undernutrition and overweight in low-income and middle-income countries. Lancet 2013, 382, 427-451. [CrossRef]

15. Horton, S.; Steckel, R. Malnutrition: Global economic losses attributable to malnutrition 1900-2000 and projections to 2050. In The Economics of Human Challenges; Lomborg, B., Ed.; Cambridge University Press: Cambridge, UK, 2013; pp. 247-272.

16. UNICEF. Improving Child Nutrition: The Achievable Imperative for Global Progress; UNICEF: New York, NY, USA, 2013.

17. National Institute of Research and Development, Ministry of Health. Basic Health Research Survey (Riset Kesehatan Dasar); National Institute of Research and Development, Ministry of Health: Jakarta, Indonesia, 2013.

18. Torlesse, H.; Cronin, A.; Sebayang, S.; Nandy, R. Determinants of stunting in Indonesian children: Evidence from a cross-sectional survey indicate a prominent role for the water, sanitation and hygiene sector in stunting reduction. BMC Public Health 2016, 16, 669. [CrossRef]

19. Bartram, J.; Cairncross, S. Hygiene, sanitation, and water: Forgotten foundations of health. PLoS Med. 2010, 7, e1000367. [CrossRef]

20. Adewuyi, E.; Adefemi, K. Behavior change communication using social media: A review. Int. J. Commun. Health 2016, 9, 109-116.

21. Naugle, D.; Hornik, R. Systematic review of the effectiveness of mass media interventions for child survival in low- and middle-income countries. J. Health Commun. 2014, 19, 190-215. [CrossRef]

22. Scott, B.; Schmidt, W.; Aunger, R.; Garbrah-Aidoo, N.; Animashaun, R. Marketing hygiene behaviours: The impact of different communication channels on reported handwashing behaviour of women in Ghana. Health Educ. Res. 2008, 23, 392-401. [CrossRef]

23. Hall, C.; Syafiq, A.; Crookston, B.; Bennett, C.; Hasan, M.; Linehan, M.; West, J.; Torres, S.; Dearden, K. Addressing communications campaign development challenges to reduce stunting in Indonesia. Health 2018, 10, 1764. [CrossRef]

24. Wakefield, M.; Loken, B.; Hornik, R. Use of mass media campaigns to change health behaviour. Lancet 2010, 376, 1261-1271. [CrossRef]

25. Curtis, V.; Cairncross, S. Effect of washing hands with soap on diarrhea risk in the community: A systematic review. Lancet Infect. Dis. 2003, 3, 275-281. [CrossRef]

26. Curtis, V.; Danquah, L.; Aunger, R. Planned, motivated and habitual hygiene behaviour: An eleven-country review. Health Educ. Res. 2009, 24, 655-673. [CrossRef] [PubMed]

27. Curtis, V.; Schmidt, W.; Luby, S.; Florez, R.; Toure, O.; Biran, A. Hygiene: New hopes, new horizons. Lancet Infect. Dis. 2011, 11, 312-321. [CrossRef]

28. Biran, A.; Tabyshalieva, A.; Salmorbekova, Z. Formative research for hygiene promotion in Kyrgyzstan. Health Policy Plan. 2005, 20, 213-221. [CrossRef]

29. Waterkeyn, J.; Cairncross, S. Creating demand for sanitation and hygiene through community health clubs: A cost-effective intervention in two districts in Zimbabwe. Soc. Sci. Med. 2005, 61, 1958-1970. [CrossRef] 
30. Wilson, J.; Chandler, G. Sustained improvements in hygiene behaviour amongst village women in Lombok, Indonesia. Trans. R. Soc. Trop. Med. Hyg. 1993, 87, 615-616. [CrossRef]

31. Greenland, K.; Iradati, E.; Ati, A.; Maskoen, Y.; Aunger, R. The context and practice of handwashing among new mothers in Serang, Indonesia: A formative research study. BMC Public Health 2013, 13, 830. [CrossRef]

(C) 2020 by the authors. Licensee MDPI, Basel, Switzerland. This article is an open access article distributed under the terms and conditions of the Creative Commons Attribution (CC BY) license (http://creativecommons.org/licenses/by/4.0/). 